\title{
O DIREITO AMBIENTAL EM PERSPECTIVA: da hermenêutica-sistêmica ao saber ambiental
}

\author{
Erivaldo Moreira Barbosa \\ Pós-Doutor em Educação pela UFPB/PPGE (2010), tendo desenvolvido pesquisa com \\ o Projeto: Direito Político/Educacional do Voto Feminino Brasileiro: da Constituinte à \\ Constituição de 1934. Doutor em Recursos Naturais pela Universidade Federal de Campina \\ Grande - UFCG (2006), na Área: Recursos Hídricos. Tese de Doutorado - Gestão de Recursos \\ Hídricos da Paraíba: uma análise jurídico-institucional. Mestre em Ciências Jurídicas pela \\ Universidade Federal da Paraíba - UFPB (1998), na Área: Direito Econômico. Especialista \\ em Economia Rural pela Universidade Federal da Paraíba - UFPB (1998). Graduado em \\ Direito pela Universidade Estadual da Paraíba - UEPB (1995). Professor Adjunto III da \\ Universidade Federal de Campina Grande - UFCG, no Curso de Bacharelado em Direito do \\ Centro de Ciências Jurídicas e Sociais. Professor e Orientador do Mestrado e Doutorado em \\ Recursos Naturais da UFCG/PPGRN e de Especialização em Direito do CCJS/UFCG. Autor \\ dos livros: "Direito Constitucional: uma abordagem histórico-crítica"; "Direito Ambiental: \\ em busca da sustentabilidade"; "Introdução ao Direito Ambiental"; "Introdução ao Estudo do \\ Direito"; "História Ambiental e Direito Ambiental: diálogos possíveis"; "Direito Ambiental \\ e dos Recursos Naturais: biodiversidade, petróleo e águas". Organizador do livro "Gestão \\ dos Recursos Naturais: uma visão multidisciplinar". Capitulo do livro "Trabalhador Rural", \\ intitulado: "O Trabalhador Rural na Região Nordeste". Capítulo do livro "Água Doce: Direito \\ Fundamental da Pessoa Humana". Experiência na área de Direito, com ênfase em Direito \\ Constitucional, Direito Ambiental, Direito Econômico, Direito de Águas. Pesquisador e \\ Coordenador de Projeto de Pesquisa Financiado pelo CNPq
} End.: Eletrônico: erifat@terra.com.br

\begin{abstract}
Maria de Fátima Nóbrega
Doutora em Recursos Naturais pela Universidade Federal de Campina Grande - UFCG (2010) na Área: Sociedade e Recursos Naturais e Linha de Pesquisa: Desenvolvimento, Sustentabilidade e Competitividade. Mestrado em Ciências da Sociedade pela Universidade Estadual da Paraíba - UEPB (1999). Graduação em Administração de Empresas pela Universidade Federal da Paraíba - UFPB (1995). Especialização em Gestão Empresarial pela Universidade Estadual da Paraíba (1996). Professora Adjunta I da Universidade Federal de Campina Grande - UFCG. Tem experiência na área de Administração, com ênfase em Gestão Ambiental, Sustentabilidade e Competitividade. Pesquisadora em Projeto de Pesquisa financiado pelo CNPq. Organizadora do livro "Gestão dos Recursos Naturais: uma visão multidisciplinar". Líder do Grupo de Pesquisa GEPASC (Grupo de Estudo em Pesquisa Ambiental, Sustentabilidade e Competitividade). Professora Colaboradora do Programa de Pós-Graduação em Recursos Naturais. End.: eletrônico: mfnbarbosa@hotmail.com
\end{abstract}

\section{RESUMO}

O objetivo é interpretar e compreender os princípios da Política Nacional do Meio Ambiente - PNMA - contidos na Lei Federal n. 6.938/81, a partir dos fundamentos (epistemológicos e jurídicos) ambientais construídos. $\mathrm{O}$ método é hermenêutico-sistêmico, o qual vasculha todo o trajeto investigativo, desde os fundamentos epistêmicos ecológicos até o processo interpretativo principiológico da lei em alusão. Dos contextos selecionados, com- 
preende-se que o saber ambiental, a Teoria da Biota Portátil e a Teoria da Intracolonização Ecológica, combinados com o Direito Ambiental, unemse em condições fortalecidas, gerando condições para se interpretar a lei em concepções alargadas. Assim, do processo interativo epistemológico, associado ao movimento interpretativo dos princípios da lei, projeta-se um sistema de natureza ambiental sustentável.

Palavras-chave: Jurídico. Interpretação. Meio ambiente. Sistema.

\title{
THE ENVIRONMENTAL LAW IN PERSPECTIVE: From Systemic Hermeneutics To Environmental Knowledge
}

\begin{abstract}
The objective of this paper is to interpret and understand the principles of the National Policy on Environmental - that is written on Federal Law $n^{\circ}$ $6.938 / 81$, from the fundamentals (epistemological and legal) environmental built. The method is systemic hermeneutics, that investigates since the fundamentals ecological epistemic to principles interpretative process of the law in allusion. From the selected contexts, it is understood that the environmental knowledge, the theory of the portable biota and the theory of the intra ecological colonization, combined with the Environmental Law, they unite in a condition strengthened, resulting in a condition to interpret the law, in conceptions extended. Therefore, from the interactive epistemological process, associated with the interpretative movement from the law principles, design a system of environmental nature sustainable.
\end{abstract}

Keywords: Legal. Interpretation. Environment. System. 


\section{INTRODUÇÃO}

O meio ambiente brasileiro é constituído de vários ecossistemas, os quais apresentam características bastante diferentes. Esses ecossistemas foram produzidos em plúrimos contextos, bem como tempos ecológicos, históricos e biológicos distintos. $\mathrm{O}$ mosaico ambiental pátrio não apresenta uma uniformidade espacial-temporal, pois coexistem no mesmo limite geográfico pátrio regiões com temperaturas baixas na região Sul e clima ameno e localidades semiáridas e altas temperaturas na região Nordeste.

Por outro lado, o meio ambiente, por ser uma dimensão sistêmica $^{1}$ - conjunto de partes que forma o todo -, permite que sejam descortinados determinados elementos em seu interior fazendo florescer um processo comunicacional que, para funcionar com fluidez, requer que as partes (informações) se encaixem de forma lógica. Destarte, dados burilados de autores estrangeiros (Greco, 2008; Capra, 1982/2002; Morin, 1996/1999/2005; Crosby, 1993; Dean, 1996; Leff, 2010; Thomas, 1988; Maturana e Varela, 2004; Gerbi, 1996; Schleiermacher, 1999) e brasileiros (Christofolleti, 1999; Streck, 2009; Boff, 2012; Comparato, 2006; Vasconcellos, 2002; Milaré, 2001) são pinçados e detalhadamente combinados e recombinados com o escopo de dotar o sistema ambiental brasileiro (em sua forma teórica) de mais embasamento filosófico/epistemológico.

As informações oriundas desses pensadores nem sempre foram trabalhadas pelo viés da finalidade. Ao realizarem seus escritos, muitos desses epistemólogos nem pensaram em evitar poluições, degradações e deteriorações nos ecossistemas brasileiros. Ainda assim, suas teorias e experiências são atividades preciosas ao campo do saber-fazer ambiental pátrio.

O Direito Ambiental - de natureza interdisciplinar - em sentido lato, ao se valer de tais dados e/ou informações, ajudará em muito na compreensão da Política Nacional do Meio Ambiente - PNMA -, em face da ética ambiental contida nestes escritos alienígenas. O alargamento das teorias e dos conceitos, além das pesquisas empíricas desenvolvidas nos contextos geográficos internacionais e no pátrio, serve para desvendar as estruturas recônditas dessa política.

De posse das informações ecológicas dos autores, se finda a primeira etapa da pesquisa. Imediatamente aos dados anteriores burilados, 
passam-se em revista os princípios da Lei n. 6.938/81 observando sua disposição, em seus pontos harmônicos e polêmicos. Os princípios, em suas particularidades, são devidamente esclarecidos por meio do método hermenêutico-sistêmico. Em síntese apertada, a junção das componentes descritas ao trocar informações entre si gera um circuito de conhecimento global-nacional sistêmico, útil ao debate entre a política, o direito e o meio ambiente.

Considerando esse contexto, objetiva-se interpretar e compreender os princípios da PNMA contidos na Lei Federal n. 6.938/81, a partir dos fundamentos (epistemológicos e jurídicos) ambientais.

\section{PROBLEMATIZAÇÃO SOBRE A POLÍTICA NACIONAL DO MEIO AMBIENTE}

O Brasil é um país de dimensão continental e aglutinador de diversos biomas e ecossistemas. Os contextos ambientais são múltiplos e os problemas e métodos de resolução dos problemas são variados. Assim, as poluições, degradações e deteriorações dos nossos ecossistemas ocorrem em escalas distintas, na medida em que variam entre a macro, a média e a micro escala. Todas alteram a qualidade ambiental e geram impactos negativos, os quais forçosamente devem ser contidos em níveis de conformidade com a legislação ambiental. O processo de industrialização, a agricultura intensiva e o consumo de produtos descartáveis impactam a capacidade de suporte do planeta Terra. Assim, indaga-se: quais os pontos harmônicos e polêmicos contidos no sistema proposto (teoria dos autores + experiências realizadas + interpretação dos princípios da Lei Federal n. 6.938/81) do arranjo teórico-prático-jurídico que devem ser interpretados, compreendidos, recombinados e expostos pelo Direito Ambiental brasileiro vigente?

\section{METODOLOGIA}

O método aplicado denomina-se hermenêutico-sistêmico e permite investigações verticais, horizontais e laterais da PNMA em escala nacional. Esse método permite interpretar e compreender os sentidos jurídicos das leis, dos decretos, das resoluções e entender as características implícitas dos documentos, das instituições e das entidades. Também lança seu foco para explicações científicas considerando aspectos sociais da re- 
alidade humana e ambiental, conforme Erivaldo Moreira Barbosa ${ }^{2}$. Informações jurídicas e não jurídicas relacionadas com o meio ambiente devem ser compreendidas e expostas.

A dimensão hermenêutica interpreta os textos jurídicos e os documentos não jurídicos, enquanto a dimensão sistêmica interliga as componentes jurídicas, sociais, econômicas, técnicas, filosóficas, éticas e ecológicas.

\section{FUNDAMENTOS EPISTEMOLÓGICOS AMBIENTAIS}

Os tópicos a seguir servirão de suporte para a interpretação futura dos princípios da Lei n. 6.938/81 (PNMA), ao mesmo tempo em que se interpretam os sentidos dos subtítulos em negrito, contribuindo com o método hermenêutico-sistêmico na busca de respostas à temática construída. Nessa senda, o conceito de sistema, as teorias da Biota Portátil, a Intracolonização Ecológica e o saber ambiental serão dissertados.

No livro "Compêndio de Epistemologia", John Greco ${ }^{3}$ ensina que desde os tempos antigos a Grécia já se debruçava sobre o conceito de epistemologia ou teoria do conhecimento. A epistemologia faz parte da agenda dos pensadores do passado, do presente e quiçá do futuro.

\subsection{Conceito de sistema: uma proposta em construção}

Preliminarmente busca-se conceituar o sistema, na medida em que esse, ao deflagrar o seu movimento inicial, impulsiona o processo no ambiente ecossistêmico rumo à interpretação, compreensão e exposição.

Fritjof Capra ${ }^{4}$, no livro "O Ponto de Mutação" (1982), afirma que a mudança paradigmática entre a visão mecanicista e a abordagem ecológica já apontava para a interação entre os fenômenos biológicos, físicos, sociais, culturais e psicológicos. Capra afirma que nenhuma teoria ou modelo deveria se sobrevalorizar, bem como nenhuma instituição social deveria ser mais importante que as demais, pois todas deveriam cooperar na mesma proporção.

Ao adentrar no debate, Edgar Morin ${ }^{5}$ descreve que a Teoria dos

${ }^{2}$ BARBOSA, 2006, p. 118 .

${ }^{3}$ GRECO, 2008, p. 16.

${ }^{4}$ CAPRA, 1982, p. 259-261.

${ }^{5}$ MORIN, 1999, p. 265. 
Sistemas de décadas passadas é limitada, e textualmente grafa que um sistema é uma dimensão plurifacetada que contém uma unidade complexa e informações da totalidade, bem como o complexo das relações entre o todo e as partes. É uma interação, uma imbricação de relações, ações e retroações que perfazem o sistema, além das interações se organizarem na forma, proteção, regulagem e regeneração do sistema.

Atente-se que o sistema não é uma expressão de fácil visualização no ecossistema, uma vez que exige o seu desnudamento epistemológico. Antonio Christofoletti ${ }^{6}$ atesta que o sistema é um conjunto harmônico de componentes e de interações não reveladas diretamente pelo conhecimento científico.

Assim, o pesquisador deverá desentranhar do recôndito os dados epistêmicos, tratá-los e combiná-los proporcionalmente. O sistema então pode ser descrito da seguinte forma: 1) uma parte disposta na natureza; 2) outra parte construída pelo ser humano no âmbito epistemológico. Em resumo, um sistema ecossistêmico evidencia-se da inter-relação do binômio ser humano-natureza, mas nem sempre em iguais proporções. Daí porque, havendo desigualdades e/ou desproporcionalidades, emergem os desequilíbrios ecológicos.

\subsection{Crosby e Dean: da Teoria Biota Portátil à Teoria Intracolonização Ecológica}

De plano, uma proposta inicial de um sistema ambiental sustentável deve se afastar de informações provenientes de teorias preconceituosas. As teorias eurocêntricas são desmascaradas pela teoria intitulada de Biota Portátil descrita por Alfred W. Crosby ${ }^{7}$; essa teoria desmonta discursos que defendem que os homens europeus são os únicos protagonistas e intérpretes da civilização da América. O autor advoga que a Teoria da Biota Portátil e seus membros dominantes foi um trabalho de equipe de organismos que se desenvolveram em conflito de cooperação há muito tempo. Assim, conceitua que a Biota Portátil deve ser entendida como a designação coletiva para os europeus e todos os organismos que eles carregaram consigo. Em outro jeito de compreender, os europeus, mais os seus animais (grandes, pequenos e micros) e a sua flora, penetraram no continente americano (do

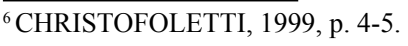

${ }^{7}$ CROSBY, 1993, p. 238-258. 
Norte e do Sul) e iniciaram o processo de degradação ambiental.

A teoria exposta acima nos permite fazer inferência e perceber que os desequilíbrios ecológicos atuais do Brasil são decorrentes de tempo histórico-biológico diferente do nosso processo de colonização. Porém, essa relação entre o passado e o presente ecológico não deve ser apreendida diretamente por essa teoria. Torna-se necessária a inserção de outra dimensão, intitulada de Intracolonização (forma endógena), que vem agressivamente poluindo e deteriorando os ecossistemas do país. Os atores sociais endógenos são os habitantes (brasileiros e estrangeiros) moradores do Brasil - associados às instituições - que desde o século XVI produzem teorias e práticas não sustentáveis.

Quanto à teoria, aqui nomeada de Intracolonização Ecológica Brasileira, acostada aos escritos de Warren Dean ${ }^{8}$, in "A ferro e fogo: a história e a devastação da Mata Atlântica brasileira" (1996), de natureza endógena, permite ser interpretada do seguinte modo: os portugueses exploradores, os governantes, os jesuítas, os madeireiros, os agricultores, os mineradores, todos sem exceção contribuíram com a devastação da floresta atlântica do Brasil. Desde tempo remoto, o país vem sendo pilhado por habitantes que por aqui circulam e, ao explorar a flora e a fauna desse espaço geográfico, ampliaram o processo de degradação que já vinha ocorrendo lentamente.

A teoria alargada por Warren Dean ${ }^{9}$ ajuda-nos na medida em que, ao introduzir em seu bojo diversos atores sociais importantes, contribui com a desconstrução de discursos oficiais, os quais elevam esses personagens ao ícone de moralidade e ética ambiental. O epistemólogo/historiador Dean, em seu trajeto ao mostrar a degradação da Mata Atlântica, do Sul ao Nordeste do país, quebra querelas dicotômicas entre o Sul (industrializado) e o Nordeste (da seca esturricada), uma vez que aglutina em sua teoria as formas de pensar e agir de todos os tomadores de decisão e formadores de opinião em sua relação tempo e espaço. Ademais, não desconsidera os atores marginais (nativos, seringueiros, ribeirinhos, mineiros, escravos), os quais não impactaram os ecossistemas, particularmente a Mata Atlântica, ao menos na mesma escala de grande magnitude dos outros atores sociais.

Essa Teoria da Intracolonização Ecológica brasileira (natureza endógena) diferencia-se da Teoria da Biota Portátil (de natureza exógena).

${ }^{8}$ DEAN, 1996.

${ }^{9}$ DEAN, 1996. 
A principal distinção entre ambas está na gênese, pois esta é mais ampla, na medida em que inclui toda a América, enquanto aquela é mais limitada e circunscrita ao Brasil. Muito embora haja diferença também entre as duas, perpassa um conduto comunicante que as une, gerando a continuidade do processo de degradação do país. Ao longo dos anos, com o avançar da tecnologia (transporte, meios de comunicação, industrialização e serviços), a Teoria da Biota Portátil e a Teoria da Intracolonização Ecológica brasileira se fundiram e, em sua forma aparente, quase não se consegue distingui-las. Enfim, a fusão das teorias gerou uma terceira vertente teórica: complexa, bastante poluidora e muito mais degradante.

\subsection{O saber ambiental}

Uma investigação que trata da PNMA requer interpretação e compreensão do saber ambiental em seus detalhes. Enrique Leff ${ }^{10}$ nos conta que o saber ambiental é exterior ao núcleo do conhecimento científico, ou seja, rejeita uma aproximação conformista. Entretanto, para que seja coerente, busca sua fundamentação no racionalismo crítico e na interdisciplinaridade e complexidade.

Destarte, ele percorre um caminho paradoxal na medida em que rejeita o conhecimento cartesiano-positivista, mas aceita se comunicar com o conhecimento contextual-sistêmico. Este, por sua vez, é interdisciplinar, complexo e ecológico. O saber ambiental expulsa determinado conhecimento e ao mesmo tempo direciona-se em sentido epistemológico. Distancia-se da objetividade e acata a intersubjetividade. É ainda uma tentativa de renúncia da racionalidade instrumental e um acolhimento de uma racionalidade ecológica. O saber ambiental não é contrário ao conhecimento; o que ele repugna é a abordagem (a)crítica. Enfim, esse saber tenta distanciar-se diametralmente dos princípios não holísticos disjuntivos, ao mesmo tempo em que produz princípios de matizes contextuais ecológicas.

Um saber ambiental não deve se descuidar do alerta que Keith Thomas $^{11}$ prescreveu, quando afirmou que tanto animais quanto plantas deveriam ter direitos a bons tratos e ser reconhecidos pelo Estado. Frise-se que esse aviso remonta ao século XVIII. A tendência descrita pelo historiador foi defendida por alguns filósofos e intelectuais da França e Inglaterra.

${ }^{10}$ LEFF, 2010, p. 11.

${ }^{11}$ THOMAS, 1988, p. 214, 215. 
Ao mesmo tempo, Keith Thomas esclarece que, apesar da haver preocupação com os animais no século XVIII, sua finalidade era utilitário-econômica com fins lucrativos. Ademais, foi promovida apenas por intermédio de petição de princípios, e somente na época contemporânea ocorreu uma defesa efetiva das plantas e dos animais.

O recorte descrito por esse historiador faz sentido na medida em que o Direito Ambiental brasileiro, ao se debruçar sobre a PNMA, leve em conta que não se deve sobrevalorizar a dimensão econômica, em face de hipotrofiar as outras componentes não menos importantes envolvida no processo.

Caso o Brasil resolva seguir os passos mostrados no recorte, dando prioridade ao lucro do grande capital, poderá se instalar uma crise ambiental em nossa PNMA, já de certa forma combalida. Uma crise instalada no âmbito do país poderá gerar ainda mais desconforto social (mais pobreza e aumento da miséria) e retrocesso na já conturbada economia brasileira. O Direito Ambiental, por ser também prescritivo, não deve se descuidar do seu rumo e disciplinar obrigatoriamente os desvios da PNMA, aproveitando-se do saber ambiental. Este, com sua epistemologia, nutrirá o Direito Ambiental, o qual sairá revigorado e contribuirá na pacificação de conflitos de natureza ecológica. Édis Milaré ${ }^{12}$ apresenta o Direito Ambiental como superação da crise ambiental, por meio de medidas coercitivas, penalidades e imposições oficiais contra os poluidores. Complementando sua escrita, escreva-se, acredita-se que a inserção da conscientização via educação ambiental também seja um passo importante na interpretação e compreensão do saber ambiental. Ora, a nova escrita desse Direito aqui proposto deverá se nutrir dos signos gráficos já delineados por Enrique Leff $^{13}$ e dos alertas e das ressalvas mostradas por Keith Thomas ${ }^{14}$.

Segundo Humberto R. Maturana e Francisco J. Varela ${ }^{15}$, conforme descrito na obra "A Árvore do Conhecimento", é necessário "conhecer o conhecer". Isso significa que conhecer tanto pode ser pela ação quanto por reflexão. Daí porque interpretar é também um ato do conhecimento (saber). Logo, interpretar-compreender os ecossistemas ambientais brasileiros é um modo de saber ambiental. Ação não é somente praticada no mundo físico, mas também nos atos reflexivos. Como exemplo de ação nos

\footnotetext{
${ }^{12}$ MILARÉ, 2001, p. 93.

${ }^{13}$ LEFF, 2010, p. 11.

${ }^{14}$ THOMAS, 1988, p. 214, 215.

${ }^{15}$ MATURANA E VARELA, 2001, p. 30.
} 
atos reflexivos tem-se como interpretar um texto escrito, interpretar uma lei ou ainda argumentar acerca dos fundamentos epistemológicos sobre o meio ambiente. Enfim, como afirmam Humberto R. Maturana e Francisco J. Varela ${ }^{16}$, toda reflexão faz brotar um mundo, de maneira que a reflexão é um fazer humano desenvolvido por alguém em particular em um determinado local.

O conhecer ocidental cartesiano/positivista oriundo do Iluminismo separa o sujeito do objeto. Segundo os autores ${ }^{17}$ ora mencionados, tal saber clama por certeza, de sorte que essa deve ser profundamente relativizada, em face da certeza somente ter algum fundamento quando compartilhada com o mundo visto pelo outro e, mesmo assim, poderá ser desconstruída por outros que se encontram fora da relação compartilhada. A certeza acerca do saber ambiental deverá ser aplicada com moderação. Por outro lado, também deverão ser acolhidos: a dúvida, a incerteza, os erros, os vieses, entre outras expressões similares. Essas dimensões marginais negligenciadas nos projetos de conotações cartesianas devem ser incluídas nos projetos de concepções sistêmico-ambientais.

O saber ambiental já não se centra mais na dicotomia entre Velho Mundo (Europa) e Novo Mundo (América), explorado e disjuntivo do sujeito e objeto. A impulsão da globalização emerge de forma arrebatadora, tentando destruir fronteiras e gerando impactos ambientais em diversas regiões e localidades. Antonello Gerbi, em seu compêndio "O novo mundo", apresenta em estilo eloquente os debates em torno das teorias eurocêntricas e seus rebatimentos na América sobre o saber ambiental. Por um trajeto instrumental da história desvenda documentos polêmicos do período compreendido entre 1750-1900 e levanta o véu da dicotomia do conhecimento acerca dos animais e das plantas existentes nos dois continentes. Buffon, De Pauw e Hegel são todos chamados ao debate, pois para Antonello Gerbi suas teses eram providas de cientificidade. Observe-se que a tese de $\mathrm{Bu}$ ffon apregoava a inferioridade dos animais da América em detrimento aos grandes animais do continente Europeu. Aliás, também fundamentava sua tese na inferioridade do clima e nas decadências fisiológicas dos animais. De Pauw segue na mesma direção ao tentar confirmar cientificamente a inferioridade do homem americano; apropriando-se da Teoria do Dilúvio Universal, alegava que a terra e o homem americano eram débeis ${ }^{18}$. Do ou-

${ }^{16}$ MATURANA E VARELA, 2001, p. 32.

${ }^{17}$ MATURANA E VARELA, 2001, p. 22.

${ }^{18}$ GERBI, 1996, p. 19-43; 56-76. 
tro flanco, Jefferson objetou as teses de Buffon e De Pauw e apresentou sua tese da superioridade da América. Destarte, mostrou ao público internacional o porte grande dos animais e a virilidade do índio americano. Outros teóricos migrados do bojo da religião saem ao encontro da tese jeffersiana e aduzem informações em prol dos animais, da flora e dos nativos americanos $^{19}$. Na obra de Gerbi ainda há espaço para a inserção da América do Sul, incluindo, nesse contexto, o Brasil.

Compreende-se que essa obra não deva ser inscrita no âmbito da teoria eurocêntrica, muito embora contenha lampejos de uma defesa velada em prol da cientificidade das teses de Buffon e De Pauw. Aqui neste artigo o que nos interessa é captar o recôndito que se imiscui por trás dessa cientificidade. Ora, ao interpretar os argumentos internos da obra, fica evidente que o conhecimento advogado por Gerbi, apud os escritos de Buffon, é na verdade um conhecimento científico cartesiano-positivista fundado em certeza e na disjunção de sujeito e objeto. Do exposto, percebe-se que a obra de Gerbi deve ser interpretada por dois prismas: o primeiro se refere à forma da linguagem e à argumentação. Em estilo brilhante e semântico, narra inúmeras diatribes entre os teóricos do Velho Continente (Europa) e o Novo Mundo (América), dando sempre continuidade lógica ao desenrolar do discurso; o segundo reporta-se às polêmicas presentes na obra, as quais contêm um viés dissimulado de objetividades, certezas e verdades, todos centrados em interpretações oriundas do referencial europeu.

O Direito Ambiental brasileiro deve rejeitar o conhecimento de visão dicotômica protagonizada pelas teorias eurocêntricas, na medida em que reifica sujeitos e desqualifica ações produzidas por outras pessoas. Igualmente, esse Direito na contemporaneidade deve ter o cuidado de não saltar para o outro extremo e desaguar no discurso da globalização, no qual tudo se permite desde que sejam afastados os contextos históricos e a crítica.

O Direito Ambiental, ao interagir com a contextualidade, critica e repugna o eurocentrismo e o globalismo; ao mesmo tempo acolhe o saber transfronteiriço solidário e os aspectos positivos da globalização hodierna. Não apenas o saber ambiental é parodoxal, como também o é o Direito Ambiental, os quais devem se relacionar com o conhecimento científico cartesiano-positivista com reservas e absorver as informações interpretadas e compreendidas dos múltiplos contextos.

${ }^{19}$ GERBI, 1996, p. 158-246. 


\section{FUNDAMENTOS JURÍDICOS AMBIENTAIS: DIREITO, HER- MENÊUTICA E MEIO AMBIENTE - DIÁLOGOS FRUTÍFEROS}

Este tópico servirá de suporte para a interpretação futura dos princípios da Lei n. 6.938/81 (PNMA), ao mesmo tempo em que se interpretam os sentidos dos subtítulos em negrito, contribuindo com o método hermenêutico-sistêmico na busca de respostas à temática construída. Desse modo, investigar-se-á a aproximação ocorrente na tríade: Direito-hermenêutica-meio ambiente.

Uma relação que deve ser investigada ocorre na esfera intercambial entre o Direito, a hermenêutica e o meio ambiente. Uma parte dessa fusão é evidente, pois a expressão denominada Direito Ambiental - que surge da imbricação vastamente conhecida do direito com o meio ambiente - já se tornou realidade. Veja-se agora a comunicação desse Direito Ambiental com a hermenêutica.

O jusfilósofo Lenio Luiz Streck ${ }^{20}$, utilizando-se do instrumento da crítica in "Verdade e Consenso", expõe o âmago dual direito/hermenêutica e em sua jusfilosofia mostra as insuficiências e os atritos entre o direito positivo e suas realizações, e questiona se é possível interpretar e aplicar o direito por intermédio do método hermenêutico tradicional.

O percurso escolhido em nosso artigo ora exposto talvez não seja contaminado por essa insuficiência, e é quase certo prever o distanciamento dessa rota de colisão, baseando-se em dois pressupostos, a saber: 1) a hermenêutica proposta é unida a uma abordagem sistêmica que religa as macrodimensões (econômicas, tecnológicas, sociais, jurídicas, políticas, éticas e ecológicas) do problema; 2) a hermenêutica proposta age em todo o processo ecossistêmico, desde os fundamentos epistemológicos, seguindo pelas bases jurídicas e culminando com o ato interpretativo principiológico da Lei n. 6.938/81(PNMA), ajustando o seu foco no ato da ação-reflexiva.

Essa resposta é necessária porque cria condições para poder interpretar, compreender e aplicar o Direito Ambiental em determinadas situações. Porém, existem limitações, isto é, em contextos mais amplos a escala metodológica adotada neste artigo requer o auxílio de alternativas

$\overline{{ }^{20} \text { STRECK, 2009, p. 1-16. }}$ 
epistemológicas. Lenio Luiz Streck ${ }^{21}$ tem razão quando ao longo da obra "Verdade e Consenso" expõe as teorias jurídicas e da argumentação do país, e arremata com a impossibilidade da construção do discurso do Direito atual na resolução de demandas hodiernas. Uma condição sine qua non ao Direito Ambiental para alcançar futuramente uma interpretação sustentável sobre a lei em discussão é aceitar a introdução do conceito de sustentabilidade.

Leonardo Boff, em seu livro "Sustentabilidade: o que é - o que não é" (2012), dá sua parcela contributiva ao falar da sustentabilidade como questão de vida ou morte e traz reflexão sobre a criação do documento intitulado de Carta da Terra recheado de valores e princípios a serem compartilhados $^{22}$ por todas as pessoas físicas ou jurídicas. Ao dissertar sobre o termo sustentabilidade, Boff aborda o desenvolvimento sustentável e mostra as dissimulações da parte especulativa do grande capital. Descredencia instituições e/ou autoridades de fazerem uso indevido da efetiva sustentabilidade ambiental e apresenta, através de um jeito epistemológico e poético, todas as facetas da insustentabilidade ${ }^{23}$ : econômico-financeira, social e planetária. Em resumo, mostra um conceito de sustentabilidade ambiental sistêmico ao conectar o planeta Terra, o cosmo, as comunidades ecológicas, os saberes, o desenvolvimento, a consciência e a vida de todos os seres vivos.

Impende assinalar que o Direito Ambiental, tomando por premissa ser um direito sustentável, forçosamente se abrirá a novos horizontes e buscará com a hermenêutica-sistêmica desnudar o espírito da lei em alusão. O Direito Ambiental emprega como meio a hermenêutica e poderá alcançar seus fins desejados, caso se valha do Princípio da Sustentabilidade Sistêmica.

Interessante observar em retrospectiva, in "Ética", de Fábio Konder Comparato ${ }^{24}$, que o positivismo jurídico atua como se estivesse totalmente separado da moral e do sistema, ou seja, a soma das partes que perfaz o todo. Alguns positivistas acreditam que o sistema normativo se realiza independente da moral, da concretude econômica ou das formas de organização política. A crença de um mundo jurídico nesse prisma circunscreve-se ao campo normativo como se fosse um sistema fechado.

\footnotetext{
${ }^{21}$ STRECK, 2009.

${ }^{22}$ BOFF, 2012, p. 13.

${ }^{23}$ BOFF, 2012, p. 17-29.

${ }^{24}$ COMPARATO, 2006, p. 350.
} 
Ora, o Direito Ambiental é circundado por um sistema aberto e caso não aceite uma aproximação com a sustentabilidade ecológica mostrada por Leonardo Boff avizinha-se ao positivismo jurídico, já referido por Fábio Konder Comparato, e aí, sim, descambará para o processo de insuficiência observado por Lenio Luiz Streck. Essa possível caminhada, ao acontecer, não alcançará o desiderato da interpretação alargada e limitará as realizações da produção do Direito Ambiental, bem como não se conhecerão os aspectos qualitativos da compreensão do recôndito da aplicação da lei que trata a PNMA.

O teólogo/filósofo/filólogo Friedrich D. E. Schleiermacher ${ }^{25}$, ao externar o seu pensamento no livro "Hermenêutica: arte e técnica de interpretação", diz que a hermenêutica era insuficiente para lidar com interpretações. A hermenêutica em sua época (1829) era muito limitada, facetada por concepções particulares e específicas. Assim, propôs uma hermenêutica de abordagem sistêmica, com possibilidades de interpretações mais complexas.

Lá se vão quase 200 anos de percepção desse autor, e ainda hoje se busca um método hermenêutico que alcance o equilíbrio interpretativo, quer dizer, um método que não seja reducionista e insuficiente, como também não tenha a pretensão de conceber a totalidade do saber. O Direito Ambiental, ao funcionar como se fosse um diapasão, ao se valer do diálogo entre a hermenêutica, o sistema e a sustentabilidade em proporção aceitável, poderá atuar em prol de responder satisfatoriamente ou minimizar as necessidades das demandas contidas na PNMA.

Grosso modo, o Direito Ambiental deverá seguir uma diretriz afastadora de ambos extremos. Atente-se que em um dos polos figura a hermenêutica reducionista; no outro, desponta a hermenêutica totalizadora. Aquela é limitada, não responde aos inúmeros questionamentos formulados pela epistemologia contemporânea e não atende as múltiplas demandas da sociedade vigente. Esta quer dar conta de toda a diversidade e exaure-se na metafísica e na pretensão da universalidade. Diante disso, a construção da hermenêutica-sistêmica emerge como solução para o impasse. De plano, assume o seu lugar no cenário epistemológico, ao aceitar suas limitações e paralelamente mostrar suas potencialidades. Incorpora assim o impacto ante as críticas e opera no interior de contextos. Entretanto, tem dificuldade de relacionamento com conhecimento científico cartesiano/po-

${ }^{25}$ SCHLEIERMACHER, 1999. 
sitivista, na medida em que incorpora dimensões rejeitadas por este tipo de conhecimento.

Logo, termos como simplicidade, objetividade e estabilidade do conhecimento tradicional são trocados pelas expressões complexidade, instabilidade e intersubjetividade do pensamento sistêmico, conforme descreve Maria José Esteves de Vasconcellos ${ }^{26}$. A hermenêutica-sistêmica, à luz do pensamento sistêmico, poderá se irradiar pelos contornos dos ecossistemas e quiçá deflagrar uma centelha no Direito Ambiental, fazendo fluir o processo interpretativo.

Sabe-se que a mudança do pensamento tradicional para o pensamento sistêmico pertence à arena da cultura e não será rápida nem simples sua reversão. Essa mudança de paradigma é da gênese da complexidade. Teóricos como Leff, Capra e Morin se debruçam sobre o tema e arrastam consigo interpretações, compreensões e aplicações de atos reflexivos. Eis o momento de caminhar ao lado do pensamento exteriorizado de Edgar Morin, in "Ciência com Consciência", quando grafa que a complexidade não deve ser vista como resposta, e sim como desafio e motivação para pensar. A mesma relaciona-se com as incertezas, as desordens e o acaso. Sua compreensão não é linear, é circular. Ela exige que se pense nos conceitos sem jamais serem dados por concluídos; é um porvir que visa ultrapassar os sistemas fechados e buscar articulações entre as coisas e entes disjuntos

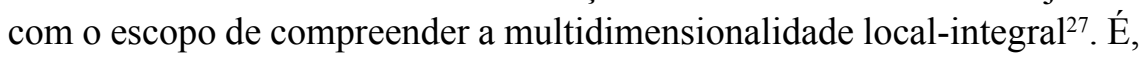
antes de tudo, uma briga dos conceitos, a parte e o todo.

Edgar Morin (2005), em outro compêndio intitulado "O Método 2: a vida da vida", alerta:

Todo sistema constitui uma unidade complexa comportando diversidade, multiplicidade, e até antagonismo. Os sistemas vivos e o sistema da vida no seu conjunto (ecossistema, biosfera) dão ao termo complexo um sentido pleno: plexus (entrelaçamento) vem de plexere (entrelaçar). O complexo - aquilo que está entrelaçado em conjunto - constitui um tecido estreitamente unido, embora os fios que o constituam sejam extremamente diversos. A complexidade viva é a diversidade organizada ${ }^{28}$.

Ao interpretar esse conceito, logo no início apreende-se que um sistema é sempre complexo e se perfaz com inúmeras partes que ora se

\footnotetext{
${ }^{26}$ VASCONCELLOS, 2002, p. 102.

${ }^{27}$ MORIN, 1999, p. 175-193.

${ }^{28}$ MORIN, 2005, p. 402.
} 
harmonizam ora se conflitam. Essa complexidade - se queira ou não -, em tempo passado já penetrara no método hermenêutico-sistêmico, e este somente pode começar a operar se conseguir contornar os conflitos internos provocados pela complexidade. As relações sujeito-objeto (biosferaecossistema) devem ser pacificadas em períodos razoavelmente estáveis, e desta feita o sistema metodológico funcionará impulsionando o Direito Ambiental a produzir resultados esperados pela sociedade, Estado, organizações não-governamentais e organismos internacionais.

Muito embora o diálogo entre o Direito, a hermenêutica e o meio ambiente seja proveitoso, ainda existe um paradoxo a se resolver na relação sujeito/objeto. Na obra "O Problema Epistemológico da Complexidade", Edgar Morin ${ }^{29}$ lavra ao longo dos capítulos que o mundo que a ciência quer conhecer tem de ser um mundo objetivo, independente de seu observador, mas este mundo não pode nunca ser percebido e concebido sem a presença e a atividade desse observador. Ainda argumenta que a objetividade tão somente conseguirá se relacionar com a subjetividade se aceitar a inclusão do sujeito, da cultura e da sociedade em seus projetos de concepção científica.

A tríade Direito-hermenêutica-meio ambiente incorpora os termos listados por Morin, na medida em que o Direito Ambiental pertence ao duplo campo cultural-social e nossa hermenêutica liga-se a um sistema aberto inclusivo e recepcionista do sujeito.

Em arremate, o método hermenêutico-sistêmico construído por meio da filosofia/epistemologia descortina os fundamentos (epistemológicos e jurídicos) ambientais e posiciona-se em condição de ajustar sua lente de observação para a estrutura dos princípios da Lei n. 6.938/81 da PNMA e interpretar sua aplicabilidade em contextos ecossistêmicos.

\section{INTERPRETAÇÃO DOS PRINCÍPIOS DA POLÍTICA NACIO- NAL DO MEIO AMBIENTE (LEI FEDERAL N. 6.938/81): SEME- LHANÇAS, HARMONIAS, DESACORDOS E CONFLITOS}

Eis o momento de jungir o método hermenêutico-sistêmico e o Direito Ambiental, ambos já contemplados com informações procedentes dos fundamentos (epistemológicos e jurídicos) ambientais, gerando, pois, uma sinergia. Assim, o método e o Direito alcançarão o cerne interpretati-

${ }^{29}$ MORIN, 1996. 
vo e compreensivo dos princípios da Política Nacional do Meio Ambiente exposta na lei em discussão.

Ao interpretar a epígrafe acima, se observa que o trajeto seguirá a diretriz não apenas das semelhanças, harmonias e dos consensos, mas também as diferenças, os desacordos, as polêmicas e os conflitos. Neste momento buscam-se os pontos de contatos, as características relacionais que unem os fundamentos (epistemológicos e jurídicos) ambientais, associado aos preceitos normativos principiológicos da lei que versa sobre a PNMA. O escopo é a organização estrutural da lei, em harmonia com os fundamentos produzidos. Dando sequência, desponta o Direito Ambiental, já enriquecido com as informações filosófico-jurídico-ecológicas, o qual se filia ao método hermenêutico-sistêmico, que então decompõe a espinha estrutural da Lei, quais sejam, os princípios da PNMA. Eis o momento de mostrar os pontos harmônicos/polêmicos previamente debatidos neste artigo:

Os princípios gerais previstos no preceito $2^{\circ}$ da lei em questão são dimensões pensadas e expostas por meio da produção legiferante do legislador. Sua ação-reflexiva ${ }^{30}$ elegeu os incisos I ao X, interpretando, compreendendo e aplicando essas funções no processo legislativo, em respeito aos ditames previstos no Art. 59 e seguintes da Constituição Federal (1988).

A elasticidade do inciso I, que diz "ação governamental na manutenção do equilíbrio ecológico, considerando o meio ambiente como um patrimônio público a ser necessariamente assegurado e protegido, tendo em vista o uso coletivo", vai ao encontro dos fundamentos epistemológicos quando trata de uma ética ambiental. Esta é exigida tanto no princípio em comento quanto na narrativa posta por Warren Dean em tópico retro. A exigência determinada do preceito em comento visa ao interesse público e a narrativa listada por Dean galga desnudar o discurso oficial da moralidade ética, em sua perspectiva dissimulada. Sem embargo, Warren Dean, ao desmascarar o discurso falso oficial, torna-se porta-voz de parte da sociedade, e por consequência relaciona-se com o interesse social, ainda que ele não o saiba.

Quanto ao inciso II, a lei exige a racionalização do uso do solo, do subsolo, da água e do ar. Atente-se que Leonardo Boff, ao lavrar sobre o tema sustentabilidade ambiental, cobrava das pessoas físicas e/ou jurídicas

${ }^{30}$ Ver Humberto R. Maturana e Francisco J. Varela, in tópico retro. 
atitudes racionais e éticas impeditivas do alastramento do grande capital em ecossistemas pátrios. Chegou ao ápice de desqualificar instituições que se intitulam sustentáveis, atuando de forma dissimulada no cenário mercadológico-financeiro. A racionalização do inciso II, interpretada em um viés alongado aglutinador (do bom senso, do não desperdício, da moderação e da parcimônia) tangencia com a escrita sustentável levada a um plano radical por Boff. Ambas as exigências, a legal e a epistemológica, se ligam e de forma cogente exigem práticas ecológicas corretas.

Destarte, o inciso III aborda o planejamento e a fiscalização do uso dos recursos ambientais. Ora, ao interpretar as entrelinhas do preceito em comento e relacioná-lo com os fundamentos preteritamente produzidos, percebe-se que planejar é antever, é um ato-reflexivo, é levar em consideração: saberes, princípios, valores, metas e técnicas, agindo em confluência no sistema. Porém, planejar é mais que isso: é o intercâmbio de informações em diversas escalas ecossistêmicas nas formas multi, inter e transdisciplinares. O planejamento ambiental pode ser conceituado como uma busca da sociedade em sentido da preservação e conservação dos recursos ambientais de uma região, com o escopo de garantir a sua permanência nesse ambiente ${ }^{31}$.

O planejamento ambiental não é apenas uma peça técnica, econômica, jurídica ou ecológica, é uma interação dessas dimensões figurante da arena da política. Assim, os fundamentos epistemológicos retro debatidos (Teoria da Biota Portátil, Teoria da Intracolonização Ecológica, saber ambiental) também habitam esse terreno político. Logo, um planejamento dos recursos ambientais jamais deve se descuidar da comunicação com a esfera epistemológica. Daí, indaga-se: por que o planejamento ambiental de natureza pública, em grande parte, não vem sendo bem aplicado? Será pelo fato de nascer centrado em parâmetros da centralização? Não se deve olvidar que um planejamento ambiental sustentável imperiosamente deve figurar de maneira descentralizada. A administração dos ecossistemas e recursos ambientais jamais deve ficar restrita aos gabinetes e instituições públicas, na medida em que alguns entes privados, especificamente o povo organizado e as ONGs, devem fazer parte ante as demandas irrealizáveis exclusivamente pela máquina estatal. Por certo, aliviaria o acúmulo de funções do Estado, ao menos em matéria ambiental. Longe da redundância, aqui se clama pelo Princípio da Participação. Em arremate, é de bom alvi-

${ }^{31}$ FRANCO, 2001, p.34. 
tre dizer que o meio ambiente é um direito fundamental da pessoa humana, de acordo com o Princípio 1 da Organização das Nações Unidas - ONU -, Conferência de Estocolmo (1972) ${ }^{32}$.

A fiscalização dos recursos ambientais carece profundamente de um saber ambiental, isto é, o saber ambiental é um condicionante da fiscalização. Dito de outro modo, para fiscalizar é necessário conhecer (saber) o problema em debate. Contudo, para fiscalizar bem, torna-se imprescindível não somente saber, mas também ser ético. De tal feita que a fiscalização dos diversos recursos ambientais, tais como a atmosfera, as águas interiores, superficiais, subterrâneas, os estuários, o mar territorial, o solo, o subsolo, os elementos da biosfera, a fauna e a flora, para que possam ser bem fiscalizados, requerem os fundamentos do saber ambiental e da ética ambiental. A fiscalização não deve ficar adstrita somente ao poder de polícia, pois as teorias formuladas por Warren Dean e Alfred W. Crosby, ao denunciarem as barbáries ecológicas, ascendem ao plano fiscalizatório. De tal modo, o instrumento de fiscalização denominado de poder de polícia do Poder Público, a teoria de Crosby (Biota Portátil) e a teoria de Dean (Intracolonização Ecológica) podem ser mutuamente consideradas instrumentos de fiscalização dos recursos ambientais.

Interpretar o inciso IV, o qual expõe sobre a proteção dos ecossistemas com a preservação de áreas representativas, pode e deve ser considerado como um hiperprincípio, uma vez que os ecossistemas e as áreas representativas contêm os recursos ambientais em seu interior. Dajoz (apud José de Ávila Aguiar Coimbra) afirma que um ecossistema pode ser entendido como um processo evolutivo maturado em tempo ecológico de grande magnitude, por meio de troca, relações e interações entre as espécies e o meio ambiente. Diz-nos ainda que um ecossistema apresenta relativa homogeneidade e estabilidade, e porta-se como um sistema aberto nas trocas de matéria e energia ${ }^{33}$.

A proteção dos ecossistemas do Brasil previsto nesse inciso IV segue na mesma direção das teorias demonstradas nos fundamentos (epistemológicos e jurídicos) ambientais, sem exceção, uma vez que todos os pensadores selecionados neste artigo apresentam em seus contextos uma moldura ambiental ecossistêmica. Dessa maneira, o Direito Ambiental, ladeando-se ao método hermenêutico-sistêmico, deverá atuar no mister de

${ }^{32}$ ONU. Conferência de Estocolmo (1972), Disponível em: <www.unep.org>, 2013.

${ }^{33}$ COIMBRA, 2002, p. 16. 
disciplinar (recuperar, prevenir ou punir) os ecossistemas e as áreas representativas do país. Ao interpretar mais detalhadamente o preceito em tela, observa-se que o Direito Ambiental requer o auxílio procedimental fiscalizatório do Poder Público, além de se valer do saber ambiental e dos fundamentos (epistemológicos e jurídicos) ambientais.

No tocante ao inciso $\mathrm{V}$, que prevê o controle de zoneamento das atividades potencial ou efetivamente poluidoras, alerta-se para a importância do regramento em alusão. Zonear uma área significa que a mesma fora esquadrinhada, dividida em partes proporcionais com a finalidade de se organizar o espaço ecossistêmico. O zoneamento aqui previsto é o zoneamento ambiental, e não o zoneamento agrário ou industrial. As características implícitas nesta modalidade ecológica envolvem o clima, o solo, a fauna, a flora, as águas, enfim, incorpora os recursos ambientais. Aliás, incorpora as dimensões bióticas e abióticas contidas no ecossistema. O zoneamento ambiental ou zoneamento ecológico-econômico (ZEE) do Brasil é um instrumento da PNMA detalhado no Decreto n. 4.297/2002.

De acordo com o Decreto mencionado, diz o Art. $2^{\circ}$, o ZEE é um instrumento de organização do território a ser obrigatoriamente seguido na implantação de planos, obras e atividades públicas e privadas, estabelecendo medidas e padrões de proteção ambiental destinados a assegurar a qualidade ambiental, dos recursos hídricos e do solo, e a conservação da biodiversidade, garantindo o desenvolvimento sustentável e a melhoria das condições de vida da população. Observe-se que o ZEE, nas atividades econômicas, deverá se preocupar com a importância ecológica, as limitações e fragilidades dos ecossistemas, às vezes impedindo a exploração do território ${ }^{34}$ pátrio por pessoas privadas ou públicas, nacionais ou estrangeiras.

As teorias dos autores Capra, Morin, Crosby, Dean, Leff, Thomas, Maturana e Varela e Gerbi forneceram argumentos e fundamentos consistentes, e do ponto de vista ambiental mostraram matizes, variando da sustentabilidade à preocupação com atividades econômicas especulativas, ecologicamente predatórias. Nesse mesmo diapasão, se coloca o ZEE detalhado no Decreto, anteriormente previsto no inciso $\mathrm{V}$ da lei interpretada.

Quanto ao inciso VI (incentivos ao estudo e à pesquisa de tecnologias orientadas para o uso racional e a proteção dos recursos ambientais), permite-se inferir sobre os fundamentos (epistemológicos e jurídicos) am-

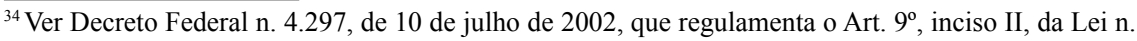
6.938/81, estabelecendo critérios para o Zoneamento Ecológico-Econômico do Brasil - ZEE.
} 
bientais, os quais podem ser considerados como estudos acerca da racionalidade e proteção dos recursos ambientais. A pesquisa, para se sustentar, carece de um contexto epistêmico e o seu modelo tecnológico deve ser o menos agressivo possível aos ecossistemas. Pergunta-se: Como a tecnologia ambiental brasileira inclusa nos programas, planejamentos, planos e projetos da PNMA vem respondendo ao procedimento principiológico mostrado neste inciso em tela? Quais os riscos escondidos nesta nebulosa relação da tecnologia com os procedimentos adotados pelo Poder Público? Uma das possibilidades de resposta à primeira indagação pode ser elaborada da seguinte forma: na maioria das vezes, a tecnologia ambiental aplicada aos espaços geográficos pátrios é procedente de um modelo de desenvolvimento econômico, centrado em uma epistemologia cartesiana-positivista, consumidora de muita energia e geradora de resíduos não recicláveis. As consequências provenientes desse modelo insustentável ocorrem nos ecossistemas, a saber: poluição das águas, esgotamento do solo, devastação das florestas, elevação da temperatura, contaminação da biosfera e atmosfera, dentre outros.

Do interpretado, alarga-se o problema e, por não serem observados os princípios da Prevenção e da Precaução, se desperdiçam somas financeiras, recursos humanos e territorialidades, ao uso de tal tecnologia; a busca pelo lucro a todo custo, de parte das empresas e parcela das pessoas físicas, associada muitas vezes à omissão do Estado, facilita a sua implementação em nosso país. A expressão ambiental é desqualificada pelo grande capital e os fundamentos epistemológicos ambientais são radicalmente rejeitados pelo discurso midiático, o qual é imposto à sociedade pelos grupos poderosos economicamente.

O interessante seria respeitar o saber ambiental em sua configuração epistemológica e trilhar pelas veredas da tecnologia socioambiental, a qual prioriza não apenas o grande capital, pois em sua PNMA incorpora a cláusula de inserção do médio e pequeno empresário, além de implementar uma tecnologia sustentável, em virtude de ser menos predatória.

O inciso VII, o qual descreve o acompanhamento da qualidade ambiental, impõe à PNMA observar exigências técnicas, com o escopo de atingir níveis desejáveis na qualidade ambiental. Por seu turno, o Conselho Nacional do Meio Ambiente - CONAMA - é um órgão consultivo e deliberativo, pertencente ao Sistema Nacional do Meio Ambiente - SISNAMA -, que estabelece, mediante proposta do IBAMA, normas e critérios para o licenciamento de atividades efetiva ou potencialmente poluidoras, a 
ser concedido pela União, por Estados, Distrito Federal e Municípios, sob supervisão do referido instituto. Determinar, quando julgar necessária, a realização de estudos das alternativas e das possíveis consequências ambientais de projetos públicos e privados, requisitando das pessoas públicas e/ou privadas e dos órgãos públicos e/ou entidades privadas as informações indispensáveis para apreciação dos estudos de impacto ambiental e respectivos relatórios, no caso de obras ou atividades de significativa degradação ambiental. Também compete ao CONAMA estabelecer, privativamente, normas, critérios e padrões relativos ao controle e à manutenção da qualidade do meio ambiente com vistas ao uso racional dos recursos ambientais, principalmente os hídricos. Afora tantas outras competências, tem o dever de deliberar sobre normas e padrões compatíveis com o meio ambiente ecologicamente equilibrado e essencial à sadia qualidade de vida ${ }^{35}$.

A qualidade ambiental exigida nos princípios da PNMA é ainda um instrumento da Lei n. 6.398/81, de acordo com o prescrito no Art. $9^{\circ}$, inciso I, e encaixa-se aos fundamentos epistemológicos descritos por Morin, Christofoletti e Dean quando se reportam aos sistemas como complexidade, harmonia e abertura para novas componentes.

A qualidade ambiental é uma condição sine qua non para a sadia qualidade de vida dos seres humanos e outros seres vivos. Dessa forma, o Poder Público deve constantemente monitorar seu parque industrial, os sistemas agroindustriais, as atividades agropecuárias e os ecossistemas de modo geral com a finalidade de medir os níveis de poluição e aferir se ultrapassam os limites permitidos pelas resoluções CONAMA. Atente-se que os níveis exigidos são expressos em unidades e medidas quantificáveis, ao passo que os fundamentos epistemológicos descritos pelos três autores supramencionados são de natureza qualitativa, porém, ambas as argumentações (quantitativa e a qualitativa) são importantes na busca efetiva de um meio ambiente ecologicamente equilibrado e à sadia qualidade de vida.

Destarte, o inciso VIII exige a recuperação de área degradas. De antemão, recuperar não é o primeiro objetivo do Direito Ambiental, quer dizer, o Direito Ambiental visa, primeiramente, prevenir. Caso não seja possível, aí, sim, objetiva-se recuperar tal local degradado. Aliás, vai além, na medida em que não sendo possível recuperar a região, aplica-se o instrumento punitivo. Frise-se ainda que a prevenção, a recuperação e a punição poderão ser aplicadas cumulativamente; por exemplo, determinada

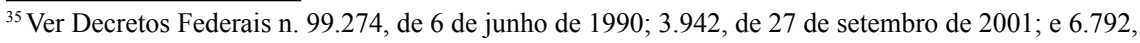
de 10 de março de 2009, do CONAMA. 
pessoa física ou jurídica praticou um dano ambiental em determinada área, com ou sem culpa, assim terá que recuperar a área, e ao mesmo tempo terá que pagar uma multa pelos danos causados ao(s) lesado(s) juridicamente.

A recuperação nem sempre é possível, pois não há como reverter, por exemplo, a devastação da Mata Atlântica ${ }^{36}$. De tal modo, é imprescindível reconhecer como consistentes os argumentos dos autores Morin, Dean e Leff, quando alertam sobre os riscos de pensar de forma disjuntivo/ positiva, uma vez que esse pensar descamba para processos degradantes e poluentes.

Quanto ao inciso X, educação ambiental a todos os níveis de ensino, inclusive à educação da comunidade objetivando capacitá-la para participação ativa na defesa do meio ambiente, fora matéria recepcionada pela Constituição Federal de $(1988)^{37}$, no Art. 225 , $\S 1^{\circ}$, inciso VI, a qual determinou que fosse criada uma lei que disciplinasse o assunto. A Lei Federal é a de n. 9.795, de 27 de abril de 1999, que dispôs sobre a Educação Ambiental ${ }^{38} \mathrm{e}$ instituiu a Política Nacional da Educação Ambiental.

Ao interpretar o dispositivo anterior, de imediato compreende-se que há um chamamento de todas as pessoas, tanto públicas quanto privadas, na tutela do meio ambiente. Assim, os fundamentos dos escritos de todos os epistemólogos selecionados, sem exceção, direta ou indiretamente se relacionam com o mandamento principiológico, e desse jeito impõem regras de comportamento à PNMA contida na Lei n. 6.938/81.

O Princípio da Educação Ambiental também deve ser visto como um hiperprincípio, em face de servir de base para as ações-reflexivas praticadas pelos inúmeros atores sociais que atuam e impactam os ecossistemas e, por extensão, o meio ambiente como um todo.

Alerta-se que os procedimentos na esfera da Educação Ambiental incorporam valores sociais, atitudes, habilidades, conhecimentos e competências, bem como intepretações, teorias e saberes acerca do meio ambiente. Nessas condições, fica evidente que a Educação Ambiental (esfera normativa) e o saber ambiental (esfera epistemológica) se fundem em um sistema que pode ser interpretado no campo da hermenêutica.

\footnotetext{
${ }^{36}$ Ver comentário, em tópico anterior, amplamente detalhado por Warren Dean.

${ }^{37}$ Ver República Federativa do Brasil, 1988.

${ }^{38}$ Ver Decreto n. 4.281, de 25 de junho de 2002, que regulamenta a Lei da Educação Ambiental.
} 


\section{CONSIDERAÇÕES FINAIS}

$\mathrm{O}$ artigo produzido centrou o seu raio de abordagem no processo interpretativo dos princípios da PNMA pertencentes à Lei Federal n. 6.938/81. Sua lente de observação direcionou preliminarmente seu foco para os fundamentos (epistemológicos e jurídicos) ambientais, alimentados por teorias e práticas de pensadores filósofos e ecólogos, internacionais e pátrios.

Dos contextos postos e compreendidos, se acolhe, por aproximações da realidade, que é possível se alcançarem respostas consistentes dos fundamentos epistêmicos (sistema, teorias e saber) conectados ao Direito Ambiental jungido a um método específico. Todo esse movimento da açãoreflexiva acontece em uma relação espaço-tempo não plenamente definida e em escala não muito alargada, uma vez que as interações, retroações e as inter-relações não são lineares, e sim processuais e carreadas de uma grande carga de complexidade.

A dinâmica do sistema ambiental que relaciona a epistemologia e o Direito transversalizada pela hermenêutica não permite uma aproximação profunda entre o pensamento cartesiano-positivista e o pensamento sistêmico-contextual. Os resultados retro abarcados desqualificam autoridades, discursos oficiais e instituições públicas de serem porta-vozes de verdades e éticas.

Interpretar legislações por meio de modelos hermenêuticos exclusivamente jurídicos é insuficiente para mostrar a essência da PNMA. Esta, por ter sua gênese na arena política, carece de outra hermenêutica que lhe desvende suas partes subjacentes. Eis que o método hermenêuticosistêmico associado ao Direito Ambiental, com seus procedimentos éticos, jurídicos e técnicos, descobre os obstáculos da PNMA e faz emergir os elos da corrente ecossistêmica.

Finalizando, sem concluir definitivamente, torna-se realizável interpretar leis baseando-se em textos e contextos de natureza filosófico/epistemológica, pois se alarga o horizonte futuro de decisões, tanto no campo do Poder Judiciário quanto no âmbito do Poder Executivo, ganhando a sociedade em duas reais situações, a saber: a) um meio ambiente equilibrado; b) uma qualidade vida saudável. 


\section{REFERÊNCIAS}

BARBOSA, Erivaldo Moreira Barbosa. Gestão de recursos hídricos da Paraíba: uma análise jurídico-institucional. Tese (Programa de Pós-Graduação em Recursos Naturais) - Universidade Federal de Campina Grande, Campina Grande - Paraíba. 2006.

BOFF, Leonardo. Sustentabilidade: o que é - o que não é. Petrópolis - RJ: Editora Vozes, 2012.

BRASIL. Constituição (1988). Constituição da República Federativa do Brasil. São Paulo: Editora Saraiva, 2010.

. Decreto Federal n. 99.274, de 6 de junho de 1990. Regulamenta a Lei n. 6.902, de 27 de abril de 1981, e a Lei n. 6.938, de 31 de agosto de 1981, que dispõem, respectivamente sobre a criação de Estações Ecológicas e Áreas de Proteção Ambiental e sobre a Política Nacional do Meio Ambiente, e dá outras providências. Disponível em: <http://www.planalto.gov.br/ccivil_03/ decreto/antigos/d99274.htm>. Acesso em: 19 out. 2013.

Decreto Federal n. 3.942, de 27 de setembro de 2001. Dá nova redação aos arts. $4^{\circ}, 5^{\circ}, 6^{\circ}, 7^{\circ}, 10$, e 11 do Decreto n. 99.274, de 6 de junho de 1990. Disponível em: <http://www.planalto.gov.br/ccivil_03/decreto/2001/D3942. htm>. Acesso em: 19 out. 2013.

Decreto Federal n. 4.297, de 10 de julho de 2002. Regulamenta o art. $9^{\circ}$, inciso II, da Lei n. 6.938, 31 de agosto de 1981, estabelece critérios para o Zoneamento Ecológico-Econômico do Brasil - ZEE, e dá outras providências. Disponível em: <http://www.planalto.gov.br/ccivil_03/decreto/2002/d4297. htm>. Acesso em: 18 out. 2013.

. Decreto Federal n. 4.281, de 25 de junho de 2002. Regulamenta a Lei n. 9.795, de 27 de abril de 1999, que institui a Política Nacional de Educação Ambiental, e dá outras providências. Disponível em: $<$ http://www.planalto.gov.br/ccivil_03/decreto/2002/d4281.htm>. Acesso em: 19 out. 2013.

. Decreto Federal n. 6.792, de 10 de março de 2009. Altera e acresce dispositivos ao Decreto n. 99.274, de 6 de junho de 1990, para dispor sobre a composição e funcionamento do Conselho Nacional do Meio Ambiente - CONAMA. Disponível em: <http:/www.planalto.gov.br/ccivil_03/_Ato20072010/2009/Decreto/D6792.htm>. Acesso em: 19 out. 2013. 
CAPRA, Fritjof. O ponto de mutação. Tradução: Álvaro Cabral. São Paulo: Cultrix, 1982.

. As conexões ocultas: ciência para uma vida sustentável. Tradução de Marcelo Brandão Cipolla. São Paulo: Editora Cultrix, 2002.

CHRISTOFOLETTI, Antonio. Modelagem de sistemas ambientais. São Paulo: Edgard Blücher, 1999.

COIMBRA, José Ávila de Aguiar. O outro lado do meio ambiente: uma incursão humanista na questão ambiental. Campinas - SP: Millenium, 2002.

COMPARATO, Fábio Konder. Ética: direito, moral e religião no mundo moderno. São Paulo: Companhia das Letras, 2006.

CROSBY, Alfred W. Imperialismo ecológico: a expansão biológica da Europa, 900-1900. Tradução: José Augusto Ribeiro e Carlos Afonso Malferrari. São Paulo: Companhia das Letras, 1993.

DEAN, Warren. A ferro e fogo: a história e a devastação da Mata Atlântica brasileira. Tradução: Cid Knipel Moreira. São Paulo: Companhia das Letras, 1996.

FRANCO, Maria de Assunção Ribeiro. Planejamento ambiental para a cidade sustentável. 2. ed. São Paulo: Annablume/FAPESP, 2001.

GERBI, Antonello. O novo mundo: história de uma polêmica: 1750-1900. Tradução: Bernardo Joffily. São Paulo: Companhia das Letras, 1996.

GRECO, John; SOSA, Ernest. (Organizadores). Compêndio de Epistemologia. Tradução: Alessandra Siedschlag Fernandes e Rogério Bettoni. São Paulo: Edições Loyola, 2008.

LEFF, Enrique. Epistemologia ambiental. Tradução: Sandra Valenzuela. 5 ed. São Paulo: Cortez, 2010.

MATURANA, Humberto R.; VARELA, Francisco J. A árvore do conhecimento: as bases biológicas da compreensão humana. Tradução: Humberto Mariotti e Lia Diskin. São Paulo: Palas Athena, 2001.

MILARÉ, Édis. Direito do ambiente: doutrina, prática, jurisprudência, glossário. 2 ed. São Paulo: Revistas dos Tribunais, 2001.

MORIN, Edgar. O problema epistemológico da complexidade. 2 ed. Lisboa 
- Portugal: Europa-América, 1996.

. Ciência com consciência. Tradução: Maria D. Alexandre e Maria Alice Sampaio Dória. 3 ed. Rio de Janeiro: Bertrand Brasil, 1999.

O método 2: a vida da vida. Tradução: Marina Lobo. 3 ed. Porto Alegre: Editora Sulina, 2005.

ORGANIZAÇÃO DAS NAÇÕES UNIDAS (ONU). Conferência das Nações Unidas do Meio Ambiente Humano, 1972. Disponível em: <http://www.unep. org/Documents.Multilingual>. Acesso em: 18 out. 2013.

SCHLEIERMACHER, Friedrich D. E. Hermenêutica: arte e técnica da interpretação. Tradução: Celso Reni Braida. 2 ed. Petrópolis - RJ: Editora Vozes, 1999.

STRECK, Lenio Luiz. Verdade e consenso: constituição, hermenêutica e teorias discursivas da possibilidade à necessidade de respostas corretas em direito. 3 ed. Rio de Janeiro: Editora Lumen Juris, 2009.

THOMAS, Keith. O homem e o mundo natural: mudanças de atitude em relação às plantas e aos animais (1500-1800). Tradução: João Roberto Martins Filho. São Paulo: Companhia das Letras, 1988.

VASCONCELLOS, Maria José Esteves de. Pensamento sistêmico: o novo paradigma da ciência. 3 ed. Campinas - São Paulo: Papirus, 2002.

Recebido: $23 / 10 / 13$

Aceito: $26 / 11 / 2013$ 